\title{
Synthesis, growth and studies of pristine and nickel doped L-valinium picrate crystals for organic light emitting diodes applications
}

\author{
A. S. Ragunathan, M. Selvapandiyan* \\ Department of Physics, Periyar University PG Extension Centre, Dharmapuri - 636 701, Tamil Nadu, India
}

\begin{abstract}
Single crystals of L-Valinium Picrate (LVP), $0.1 \mathrm{~mol} \% \mathrm{Ni}^{2+}$ doped L-Valinium Picrate, and $0.2 \mathrm{~mol} \% \mathrm{Ni}^{2+}$ doped L-Valinium Picrate were grown by low temperature solution growth method, especially by solvent evaporation technique at ambient temperature. Function groups and modes of vibration were identified by FT-IR studies. The grown crystals belong to monoclinic system which has been revealed by powder XRD. The estimated band gaps were found to be $3.86 \mathrm{eV}$ for LVP, $3.72 \mathrm{eV}$ for $0.1 \mathrm{~mol} \% \mathrm{Ni}^{2+}$ doped LVP, and $3.70 \mathrm{eV}$ for $0.2 \mathrm{~mol} \% \mathrm{Ni}^{2+}$ doped LVP crystals, respectively. The PL excitation wavelength of the grown materials is $370 \mathrm{~nm}$. All the elements $(\mathrm{C}, \mathrm{N}, \mathrm{O}, \mathrm{Ni}$, and $\mathrm{Cl})$ as per molecular formula were present in the EDAX spectrum of the grown materials. The $0.2 \mathrm{~mol} \% \mathrm{Ni}^{2+}$ ion doped LVP materials had higher thermal stability $\left(208^{\circ} \mathrm{C}\right)$ than LVP and $0.1 \mathrm{~mol} \% \mathrm{Ni}^{2+}$ doped LVP.
\end{abstract}

Keywords: crystal growth; crystal structure; nonlinear optical properties; luminescence; X-ray diffraction

\section{Introduction}

In the recent days, nonlinear optical materials have played an important role in different fields of applications such as telecommunications, optoelectronics and photonics due to high nonlinear optical nature, in particular high second harmonic efficiency $[1,2]$. Hence, satisfying the demands imposed on nonlinear optical materials attracted many young researchers towards growth of good quality single crystals that generate second order harmonics [3]. Organic nonlinear optical materials gathered greater attention than inorganic ones because of high nonlinear optical susceptibility, low laser damage threshold, large electro-optic coefficient with low frequency dispersion and large structural diversity [3]. The molecular formula of for L-Valinium Picrate is $\mathrm{C}_{5} \mathrm{H}_{11} \mathrm{NO}_{2} \cdot \mathrm{C}_{6} \mathrm{H}_{2} \mathrm{~N}_{3} \mathrm{O}_{7}$. Among all the organic nonlinear optical materials, R-amino acids exhibit a specific nature such as weak van der Waals and hydrogen bonds, wide transparency in UV as well as visible regions, and molecular chirality [4]. L-Valine and its

*E-mail: mselvapandiyan@ rediffmail.com derivatives have good optical, thermal, structural, mechanical properties which were reported by many researchers [5-9]. Among all the reported articles and to the best of our knowledge, no researcher has grown L-Valinium Picrate single crystals doped with two different concentration of $\mathrm{Ni}^{2+}$. In this communication, we report on the growth of two different concentrations of $\mathrm{Ni}^{2+}$ doped LVP single crystals. The grown crystals were analyzed by various techniques like powder XRD, UV-Vis, PL, EDAX, FT-IR and TGA/DTA and the results of these studies have been discussed in this article.

\section{Experimental work}

The market available L-Valine (Loba), picric acid (Merck) and nickel chloride hexahydrate (Merck) were purchased. L-Valinium Picrate was synthesized and grown by using L-Valine and picric acid in equal molar ratio in mixed deionized water and acetone solvent by solvent evaporation method at ambient temperature [10]. Then, the solution was stirred continuously for 6 hours to obtain clear saturated homogenous solution and the 
solution was filtered two times with Whatmann filter paper $(\Phi=125 \mathrm{~mm})$. The filtered solution was placed in an undisturbed place for slow evaporation. After keen observation, the yellow color LValinium Picrate single crystals were obtained at the end of $30^{\text {th }}$ day. L-Valinium Picrate solution was again prepared in two different beakers separately as per the above procedure and then 0.1 and $0.2 \mathrm{~mol} \%$ of nickel chloride hexahydrate was added. After an hour, the clear solution was obtained and filtered with the help of Whatmann filter paper. The filtered solution was placed in a dust free place for slow evaporation. At the end of $24^{\text {th }}$ day, the doped crystal was harvested. The photographs of as-grown pure LVP, 0.1 and $0.2 \mathrm{~mol} \%$ $\mathrm{Ni}^{2+}$ doped LVP crystals are shown in Fig. 1a, b and $\mathrm{c}$.

\section{Results and discussion}

\subsection{UV-Vis study}

Absorption spectra of the grown L-Valinium Picrate (LVP), $0.1 \mathrm{~mol} \%$ and $0.2 \mathrm{~mol} \% \mathrm{Ni}^{2+}$ doped LVP crystals were recorded in the range of $190 \mathrm{~nm}$ - $1110 \mathrm{~nm}$ by using DRS mode Thermo Fisher Evolution $220 \mathrm{UV}$-Vis spectrophotometer and are shown in Fig. 2. The maximum absorption wavelength of the grown LVP, $0.1 \mathrm{~mol} \% \mathrm{Ni}^{2+}$ and $0.2 \mathrm{~mol} \% \mathrm{Ni}^{2+}$ doped materials are $396.07 \mathrm{~nm}$, $417.40 \mathrm{~nm}$ and $424.50 \mathrm{~nm}$, respectively. There was an increase in absorption wavelength for $0.2 \mathrm{~mol} \%$ $\mathrm{Ni}^{2+}$ doped LVP crystals due to the incorporation of $\mathrm{Ni}^{2+}$ ion in LVP. The graph was also plotted between $\mathrm{h} v$ and $(\alpha \mathrm{h} v)^{2}$ (Fig. 3) to obtain the band gap values of LVP, $0.1 \mathrm{~mol} \%$ and $0.2 \mathrm{~mol} \%$ nickel doped of LVP crystals, that are $3.86 \mathrm{eV}, 3.72 \mathrm{eV}$ and $3.70 \mathrm{eV}$, respectively. Lack of absorption between $350 \mathrm{~nm}$ and $1200 \mathrm{~nm}$ was reported by Saravanan et al. [5]. The absorption of the all grown crystals is zero in the entire visible and IR regions, which is an important requirement and advantage of materials having nonlinear optical properties, intended for the use in OLED.

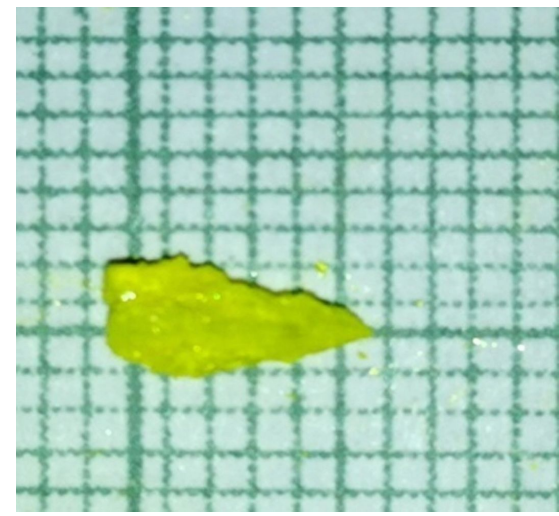

(a)

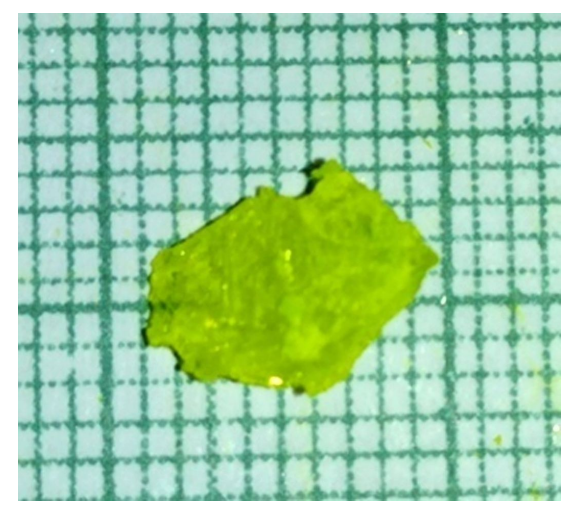

(b)

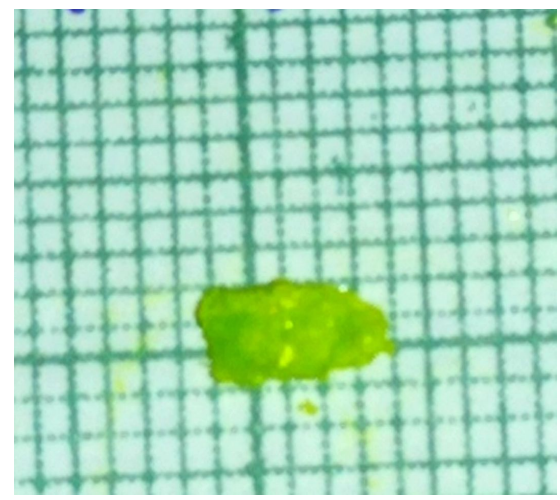

(c)

Fig. 1. a) as-grown LVP, b) as-grown $0.1 \mathrm{~mol} \% \mathrm{Ni}^{2+}$ doped LVP, c) as-grown $0.2 \mathrm{~mol} \% \mathrm{Ni}^{2+}$ doped LVP

\subsection{Powder XRD analysis}

L-Valinium Picrate single crystals were analyzed by using $X$ Pert PRO multipurpose PAN Analytical X-ray diffractometer between $0^{\circ}$ and $90^{\circ}$ with the wavelength of $1.54 \AA$. 


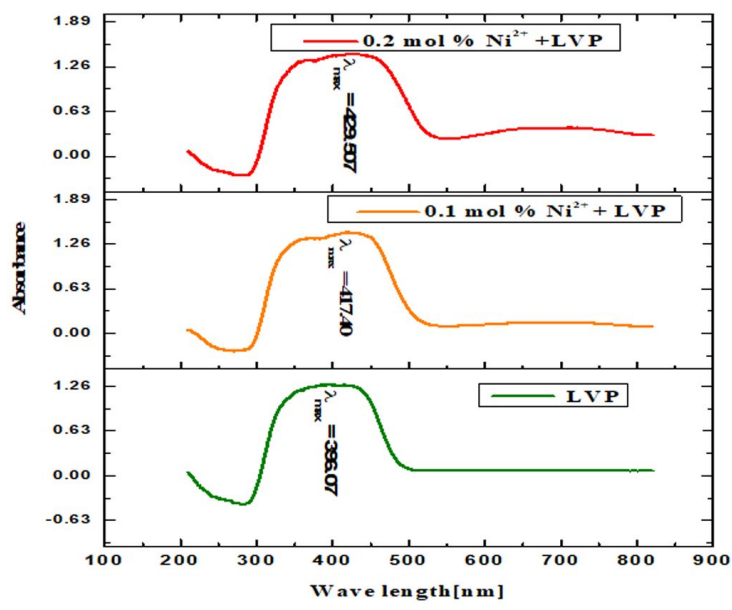

Fig. 2. Absorbance spectra of LVP, 0.1 and $0.2 \mathrm{~mol} \%$ $\mathrm{Ni}^{2+}$ doped LVP

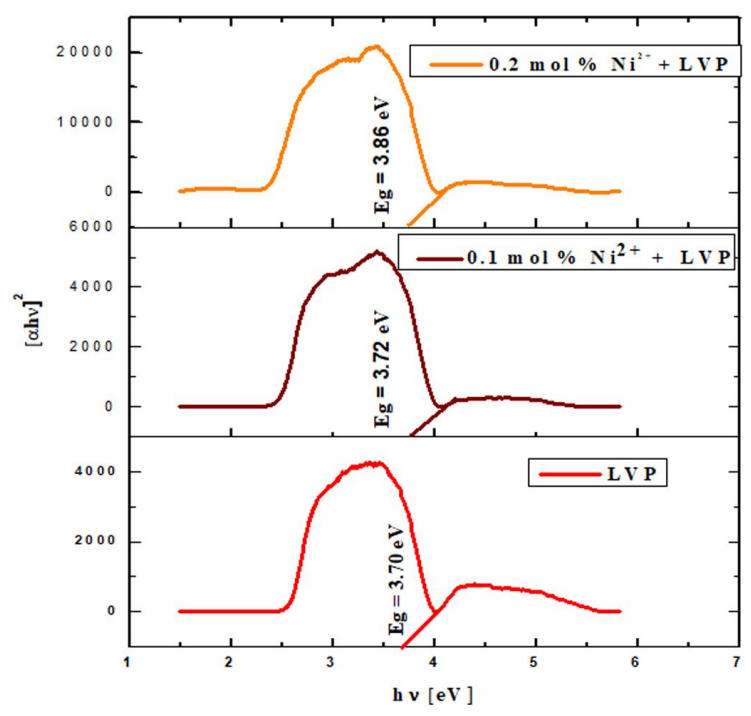

Fig. 3. UV-Vis spectra $(\alpha h v)^{2}$ vs. hv.

The well-defined sharp peaks of the patterns were indexed with the help of standard JCPDS File No. 33-1954. The values of interfacial angles and translation vectors were also determined to identify the exact crystal system of the grown materials. The determined translational vectors and interfacial angles are $\mathrm{a}=9.647 \AA, \mathrm{b}=5.255 \AA, \mathrm{c}=12.01 \AA$ and $\beta=91.40^{\circ}$ which reveals that the grown crystals belong to non-centrosymmetric monoclinic system with space group $\mathrm{P} 2{ }_{1}[11]$ and all the values are in a good agreement with reported data [3]. Hence, the

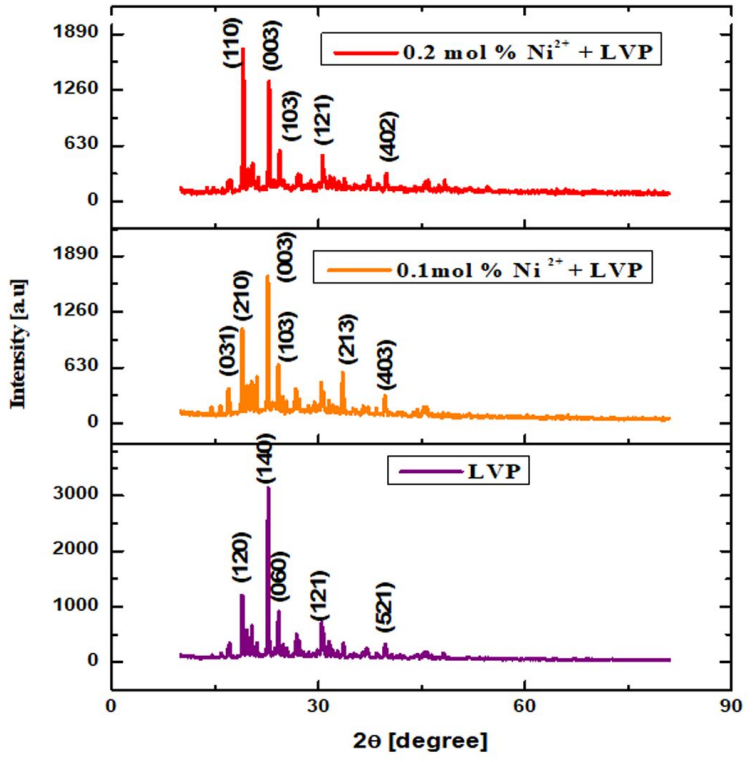

Fig. 4. Powder XRD patterns of LVP, 0.1 and $0.2 \mathrm{~mol} \%$ $\mathrm{Ni}^{2+}$ doped LVP

grown crystals are also very useful for second harmonic device fabrication [4]. All the major peaks of the doped crystals are slightly shifted due to incorporation of $\mathrm{Ni}^{2+}$ ions into LVP but the crystal system has not been altered. By using Debye- Sheerer formula:

$$
D=K \lambda / \beta \cos \theta
$$

where, $\mathrm{D}$ is the average crystallite size, $\mathrm{K}$ is the dimensionless shape factor, $\lambda$ is the $\mathrm{X}$-ray wavelength, $\beta$ is the line broadening at half the maximum and $\theta$ is the Bragg angle, the estimated average crystallite size of the grown LVP, 0.1 and $0.2 \mathrm{~mol} \%$ nickel ion doped LVP crystals are $15.34 \mathrm{~nm}, 9.594 \mathrm{~nm}$ and $3.214 \mathrm{~nm}$, respectively and their lattice strain values are $0.1364,0.152$ and 0.2728 respectively. Crystallite size of the doped materials decreased with an increase in the concentration of nickel dopants. The decrease in particle size and increase in lattice strain in the grown materials show the enhancement in their structure. The size of the $0.2 \mathrm{~mol} \%$ nickel doped LVP is smaller than that of $0.1 \mathrm{~mol} \%$ nickel doped LVP because the high concentration of the dopant reduces the grain size, by pinning the grain boundaries. 


\subsection{FT-IR analysis}

The infrared spectral analysis of the grown materials was carried out using Perkin Elmer spectrometer version 10.4.00 to determine the chemical bonding and functional groups in the wavenumber range between $4000 \mathrm{~cm}^{-1}$ and $400 \mathrm{~cm}^{-1}$. The plotted wavenumber versus transmittance FT-IR spectral graphs are displayed in Fig. 5. The vibrational frequencies and assignments of the materials are presented in Table 1. In the FT-IR spectra, the peaks at $3435,3088,1557$ and $1482 \mathrm{~cm}^{-1}$ are assigned to $\mathrm{C}=\mathrm{O}$ stretching, $\mathrm{N}-\mathrm{H}$ stretching, $\mathrm{NO}_{2}$ asymmetrical stretching and $\mathrm{CH}_{3}$ asymmetrical stretching. The $\mathrm{C}-\mathrm{O}$ stretching, $\mathrm{C}-\mathrm{N}$ stretching, $\mathrm{CH}_{2}$ rocking and $\mathrm{NO}_{2}$ wagging are assigned to the peaks at 1206, 1160, 1078, 907 and $744 \mathrm{~cm}^{-1}[12,13]$. The majority peaks of doped LVP single crystals are slightly less shifted due to the addition of $\mathrm{Ni}^{2+}$ ion in L-Valinium Picrate. The lower shifting indicates that the $0.2 \mathrm{~mol} \% \mathrm{Ni}^{2+}$ ion doped material has better quality than pure and $0.1 \mathrm{~mol} \%$ nickel ion doped LVP single crystals.

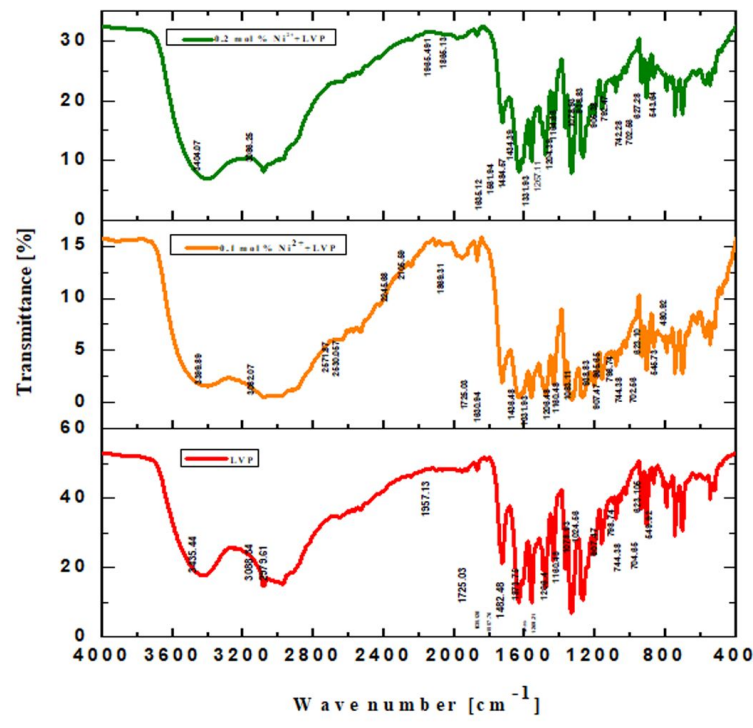

Fig. 5. FT-IR spectra of LVP, $0.1 \mathrm{~mol} \%$ and $0.2 \mathrm{~mol} \%$ $\mathrm{Ni}^{2+}$ doped LVP

\subsection{EDAX analysis}

The grown L-Valinium Picrate and $\mathrm{Ni}^{2+}$ doped L-Valinium Picrate were subjected to energy dispersive X-ray analysis using EDS BRUKER NANO GMBH D-12489 with accelerating voltage of 0 to $30 \mathrm{kV}$ to identify elemental composition of the grown crystals. Fig. 6, 7, 8 display the EDAX spectra of pure LVP, $0.1 \mathrm{~mol} \% \mathrm{Ni}^{2+}$ doped LVP and $0.2 \mathrm{~mol} \% \mathrm{Ni}^{2+}$ doped LVP. The elements (C, $\mathrm{N}, \mathrm{O}, \mathrm{Ni}$ and $\mathrm{Cl}$ ) present in the grown crystals in wt.\% have been tabulated in Table 2 .

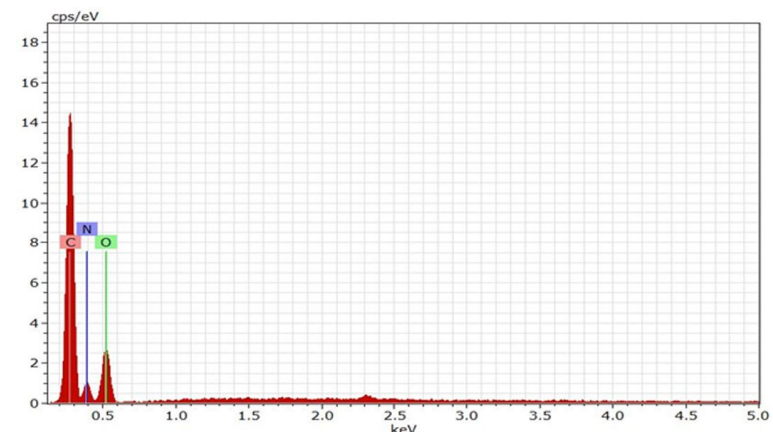

Fig. 6. EDAX spectrum of pure LVP

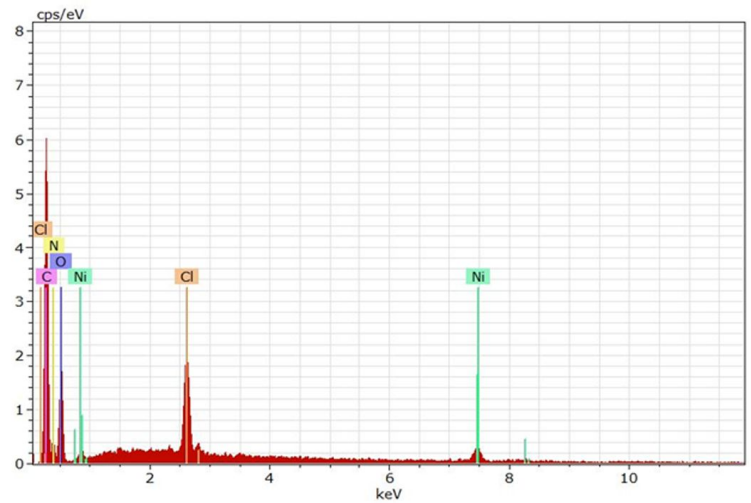

Fig. 7. EDAX spectrum of $0.1 \mathrm{~mol} \% \mathrm{Ni}^{2+}$ doped LVP

\subsection{PL studies}

Photoluminescence study is an important tool to obtain excitation wavelength and emission peak values of the materials. L-Valinium Picrate, $0.1 \mathrm{~mol} \% \mathrm{Ni}^{2+}$ ion doped LVP and $0.2 \mathrm{~mol} \% \mathrm{Ni}^{2+}$ ion doped LVP were subjected to PL studies using Varian Carry Eclipse photoluminescence spectrometer in the range of $450 \mathrm{~nm}-700 \mathrm{~nm}$ and the recorded spectra of PL are shown in Fig. 9. From the spectra, the observed excitation wavelength is 
Table 1. Vibrational frequencies and assignments of LVP and $\mathrm{Ni}^{2+}$ doped LVP

\begin{tabular}{ccccc}
\hline \multicolumn{2}{c}{ Reported [1-3] } & \multicolumn{4}{c}{ Vibrational frequencies $\left[\mathrm{cm}^{-1}\right]$} & Assignment \\
& LVP & $0.1 \mathrm{~mol}^{2} \mathrm{Ni}^{2+}+\mathrm{LVP}$ & $0.2 \mathrm{~mol} \% \mathrm{Ni}^{2+}+\mathrm{LVP}$ & \\
\hline \hline 3446 & 3435 & 3399 & 3404 & $\mathrm{C}=\mathrm{O}$ Stretching \\
3088 & 3088 & 3082 & 3086 & $\mathrm{~N}-\mathrm{H}$ Stretching \\
2968 & 2979 & 2571 & 1965 & $\mathrm{~N}-\mathrm{H}$ stretching \\
1565 & 1557 & 1557 & 1561 & $\mathrm{NO}_{2}$ asymmetrical stretching \\
1487 & 1482 & 1476 & 1434 & $\mathrm{CH}_{3}$ asymmetrical deformation \\
1215 & 1206 & 1206 & 1204 & $\mathrm{C}-\mathrm{O}$ Stretching \\
1164 & 1160 & 1160 & 1164 & $\mathrm{C}-\mathrm{N}$ Stretching \\
1079 & 1078 & 1083 & 1083 & $\mathrm{C}-\mathrm{N}$ Stretching \\
937 & 934 & 938 & 938 & $\mathrm{C}-\mathrm{H}$ out of plane e deformation \\
906 & 907 & 907 & 905 & $\mathrm{CH}$ rocking \\
746 & 744 & 744 & 742 & $\mathrm{NO}_{2}$ Wagging \\
706 & 704 & 702 & 702 & $\mathrm{COO}_{-}$Stretching \\
540 & 549 & 545 & 543 & $\mathrm{COO}_{-}$Stretching \\
\hline
\end{tabular}

Table 2. Quantification of LVP and $\mathrm{Ni}^{2+}$ doped LVP

\begin{tabular}{|c|c|c|c|c|c|c|}
\hline \multirow{2}{*}{ Elements } & \multicolumn{2}{|c|}{ LVP } & \multicolumn{2}{|c|}{$0.1 \mathrm{~mol} \%$ of $\mathrm{Ni}^{2+} \mathrm{LVP}$} & \multicolumn{2}{|c|}{$0.2 \mathrm{~mol} \%$ of $\mathrm{Ni}^{2+} \mathrm{LVP}$} \\
\hline & $\begin{array}{c}\text { Theoretical } \\
\text { [wt.\%] }\end{array}$ & $\begin{array}{c}\text { Experimental } \\
\text { [wt.\%] }\end{array}$ & $\begin{array}{l}\text { Theoretical } \\
\text { [wt.\%] }\end{array}$ & $\begin{array}{c}\text { Experimental } \\
\text { [wt.\%] }\end{array}$ & $\begin{array}{l}\text { Theoretical } \\
\text { [wt.\%] }\end{array}$ & $\begin{array}{c}\text { Experimental } \\
\text { [wt.\%] }\end{array}$ \\
\hline $\mathrm{C}$ & 57.50 & 51.77 & 57.31 & 50.35 & 58.57 & 48.54 \\
\hline $\mathrm{O}$ & 24.15 & 28.97 & 26.49 & 31.00 & 18.87 & 18.23 \\
\hline $\mathrm{N}$ & 18.35 & 19.27 & 15.17 & 15.55 & 18.22 & 20.12 \\
\hline CL & - & - & 0.79 & 2.05 & 2.79 & 6.82 \\
\hline $\mathrm{Ni}$ & - & - & 0.25 & 2.05 & 1.55 & 6.29 \\
\hline
\end{tabular}

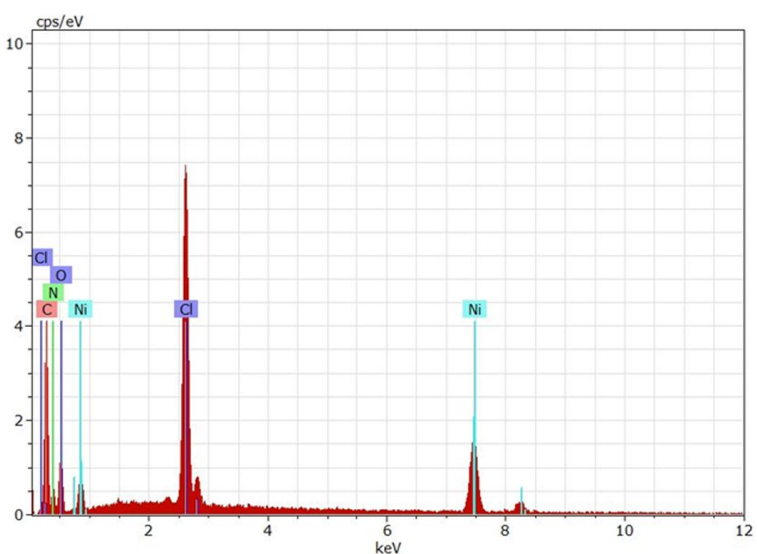

Fig. 8. EDAX spectrum of $0.2 \mathrm{~mol} \% \mathrm{Ni}^{2+}$ doped LVP

$470 \mathrm{~nm}$ and the sharp high intensity PL emission peak was obtained at $484 \mathrm{~nm}$. The PL spectra of the grown materials show one higher intensity sharp peak of blue emission at about $484 \mathrm{~nm}(2.56 \mathrm{eV})$. The other two low intensity peaks of green and red emission are observed at $486 \mathrm{~nm}(2.55 \mathrm{eV})$ and $613 \mathrm{~nm}(2.02 \mathrm{eV})$, respectively. The materials with blue and green PL emissions are very useful for OLED applications [14]. In the PL spectra, $0.2 \mathrm{~mol} \% \mathrm{Ni}^{2+}$ ion doped LVP single crystal, peaks are slightly shifted to lower wavelength and high intensity side due to higher concentration of nickel ion in the LVP, which clearly reveals that it is very useful for OLED applications.

\subsection{TGA/DTA analysis}

Thermal studies of the grown L-Valinium Picrate single crystals were carried out using simultaneous thermal analyzer (STA-600) in the temperature range of $40{ }^{\circ} \mathrm{C}$ to $600{ }^{\circ} \mathrm{C}$ at nitrogen 


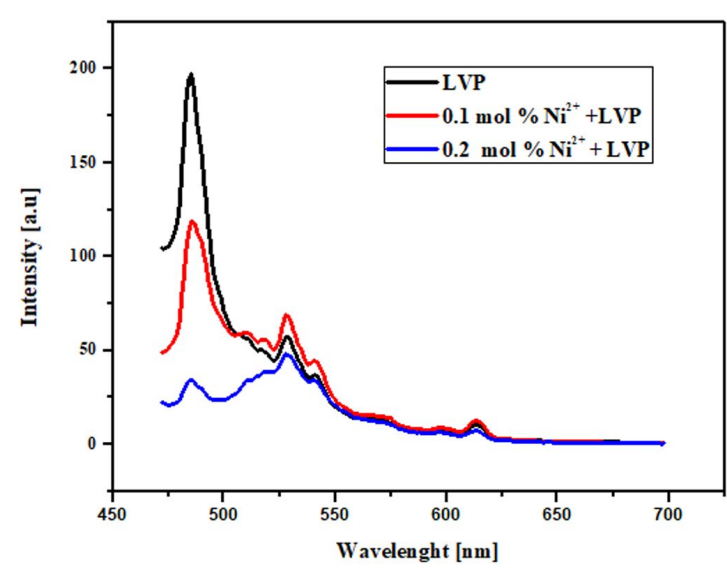

Fig. 9. PL spectra of LVP, $0.1 \mathrm{~mol} \%$ and $0.2 \mathrm{~mol} \% \mathrm{Ni}^{2+}$ doped LVP

atmosphere and a heating rate of $20{ }^{\circ} \mathrm{C} / \mathrm{min}$. The TGA/DTA curves of LVP, $0.1 \mathrm{~mol} \% \mathrm{Ni}^{2+}$ doped LVP and $0.2 \mathrm{~mol} \% \mathrm{Ni}^{2+}$ doped LVP are shown in Fig. 10, Fig. 11 and Fig. 12. The grown materials are thermally stable up to $203{ }^{\circ} \mathrm{C}$ for LVP, $204{ }^{\circ} \mathrm{C}$ for $0.1 \mathrm{~mol} \% \mathrm{Ni}^{2+}$ doped LVP and $208{ }^{\circ} \mathrm{C}$ for $0.2 \mathrm{~mol} \% \mathrm{Ni}^{2+}$ doped LVP. The endothermic peaks of the LVP, $0.1 \mathrm{~mol} \% \mathrm{Ni}^{2+}$ doped LVP and $0.2 \mathrm{~mol} \% \mathrm{Ni}^{2+}$ doped LVP single crystals were obtained at $213{ }^{\circ} \mathrm{C}, 215{ }^{\circ} \mathrm{C}$ and $216{ }^{\circ} \mathrm{C}$, which clearly shows the melting point of the grown materials. The major weight losses of about $44 \%, 43 \%$ and $31 \%$ take place between the temperatures of $203{ }^{\circ} \mathrm{C}$ and $259{ }^{\circ} \mathrm{C}$ for LVP, $204{ }^{\circ} \mathrm{C}$ and $251{ }^{\circ} \mathrm{C}$ for $0.1 \mathrm{~mol} \% \mathrm{Ni}^{2+}$ doped LVP and $208{ }^{\circ} \mathrm{C}$ and $239^{\circ} \mathrm{C}$ for $0.2 \mathrm{~mol} \% \mathrm{Ni}^{2+}$ doped LVP, respectively. The major weight losses in the materials are due to the liberation of gaseous products such as $\mathrm{CO}_{2}$, $\mathrm{NH}_{3}$, etc. The TGA/DTA curves of LVP, $0.1 \mathrm{~mol} \%$ $\mathrm{Ni}^{2+}$ doped LVP are shown in Fig. 10, 11 and 12. TGA/DTA analysis results confirm that the grown materials are very good candidates for OLED applications up to $208^{\circ} \mathrm{C}$.

\section{Conclusion}

L-Valinium Picrate (LVP), $0.1 \mathrm{~mol} \% \mathrm{Ni}^{2+}$ doped LVP and $0.2 \mathrm{~mol} \% \mathrm{Ni}^{2+}$ doped LVP single crystals were grown by solvent evaporation method at ambient temperature. Powder X-ray diffraction

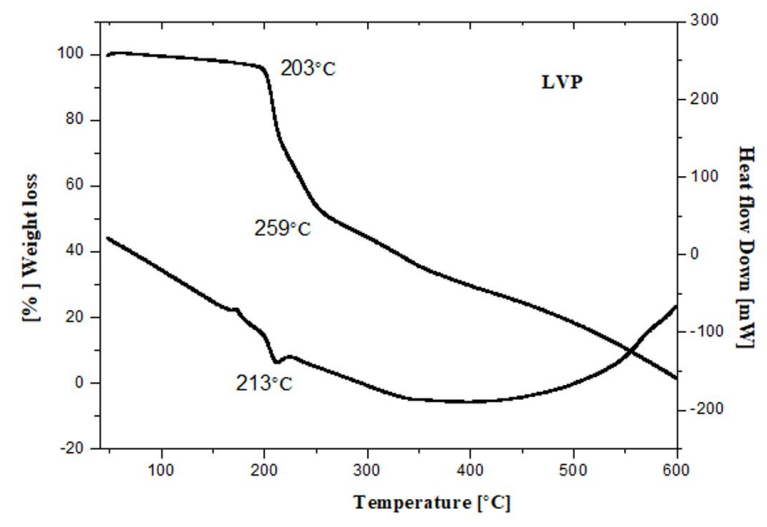

Fig. 10. TGA/DTA curves of pure LVP

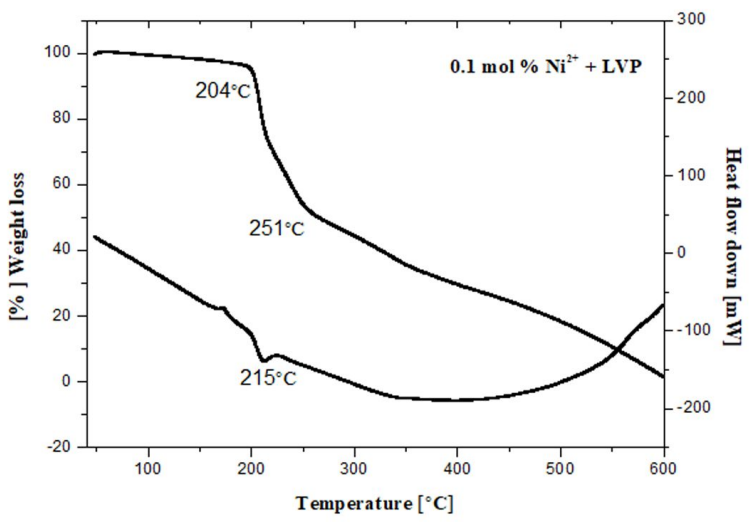

Fig. 11. TGA/DTA curves of $0.1 \mathrm{~mol} \% \mathrm{Ni}^{2+}$ doped LVP

studies revealed that the grown materials belong to the monoclinic system and space group $\mathrm{P} 2{ }_{1}$. All the peaks of the doped material were slightly shifted due to incorporation of $\mathrm{Ni}^{2+}$ ions in LVP lattice. Modes of vibrations and functional group present in the grown materials were confirmed by Fourier transform infrared studies. The maximum absorption wavelength of the grown materials is $396.07 \mathrm{~nm}$ for as-grown L-Valinium Picrate, $417.40 \mathrm{~nm}$ for $0.1 \mathrm{~mol} \% \mathrm{Ni}^{2+}$ doped LVP and $429.50 \mathrm{~nm}$ for $0.2 \mathrm{~mol} \% \mathrm{Ni}^{2+}$ doped LVP. The grown materials are thermally stable up to $203{ }^{\circ} \mathrm{C}$ for LVP, $204{ }^{\circ} \mathrm{C}$ for $0.1 \mathrm{~mol} \% \mathrm{Ni}^{2+}$ doped LVP and $208{ }^{\circ} \mathrm{C}$ for $0.2 \mathrm{~mol} \% \mathrm{Ni}^{2+}$ doped LVP. Carbon, nitrogen, oxygen, nickel, and chlorine presence in the grown materials was confirmed by EDAX. High intensity sharp PL emission peak was observed at $484 \mathrm{~nm}$. All the analysis results revealed that the 


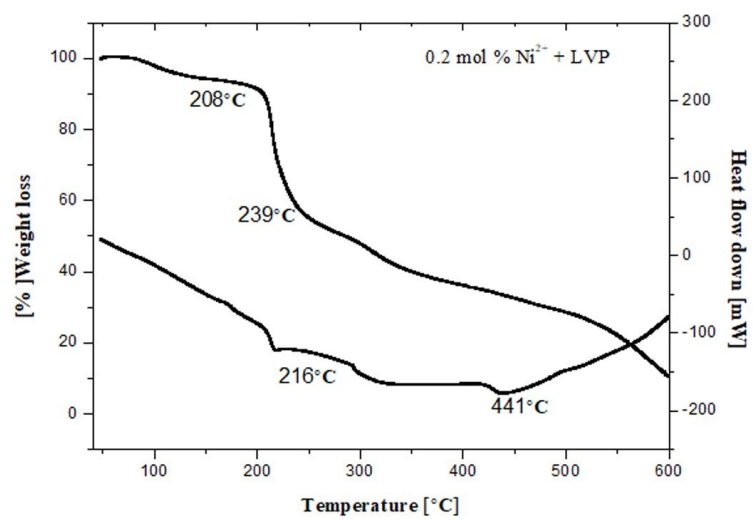

Fig. 12. TGA/DTA curves of $0.2 \mathrm{~mol} \% \mathrm{Ni}^{2+}$ doped LVP

$0.2 \mathrm{~mol} \% \mathrm{Ni}^{2+}$ doped L-Valinium Picrate single crystal is very suitable for organic light emitting diode applications (OLED).

\section{Acknowledgements}

The authors convey their gratitude to Dr. G. Ravi, Preofessor and Head, Department of Physics, Alagappa University, Karaikudi for Powder XRD, UV, and PL characterization facilities. The authors also thank Dr. S. Meenakshi, Professor and Head, Department of Chemistry, The Gandhigram Rural Institute - Deemed University, Gandhigram - 624 302, Tamil Nadu for EDAX analysis.

\section{References}

[1] Kirubavathi K., Selvaraju K., Vijayan N., KUMararaman S., Spectro Chim. Acta Part A, 71 (2008), 288-291.
[2] Williams D.J., Angew J., Chem. Int. Ed. Engl., 23 (1984), 690-694.

[3] Antony Joseph A., John David Ebenezar I., RAMACHANDRA RAJA C., Opt., 123 (2012), 1436- 1439.

[4] Sangeetha M.K., Mariappan M., MadhruamBal G., Mojumdar S.C., Opt. Mater, 108 (2012), 887-894.

[5] Saravanan M., Abraham Rajasekar S., Opt. Mater., 52 (2016), 75-86.

[6] Russel Raj K., Bhagavannarayan G., MuruGAKOOTHAN P., Opt., 124 (2013), 493-500.

[7] Senthilkumar K., BrigetMary M., RamakrISHNAN V., J. Raman Spect., 38 (2007) 288 - 294.

[8] Anitha K., Sridhar B., Rajaram K.K., Acta Cryst., E60 (2004), 1530 - 1532.

[9] SRinivasan P., Kanagasekaran T., GopalakrISHNAN R., Cryst. Growth Des., 8 (2008), 2340-2352.

[10] BRICE J C., Crystal Growth Processes, John Wiley and Sons, New York, 1986.

[11] Charles Kittle, Introduction to Solid State Physics, Seventh Edition, Wiley India, New Delhi, 2008.

[12] Silverstein Robert M., Webster Francis X., KIEMLE DAVID J., Spectrometric Identification of Organic Compounds, Seventh Edition, John Wiley \& Sons, New York, 2005.

[13] Bandwell C N., Fundamentals of Molecular Spectroscopy, Third Edition, McGRAW-HILL Book Company, New Delhi, 1983.

[14] Mahakhode J.G., .Bahirwar B.M., Dhoble S.J., Moharil S.V., In: Proc. Of ASID 06.8-12 October, New Delhi.

Received 2018-12-20

Accepted 2019-04-23 